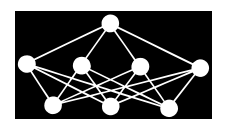

\title{
STATISTICAL FEATURE EXTRACTION BASED ON AN ANN APPROACH FOR ESTIMATING THE COMPRESSIVE STRENGTH OF CONCRETE
}

\author{
G. Doğan, M.H. Arslan $\pitchfork$. Ceylan
}

\begin{abstract}
Applications of artificial intelligence in engineering disciplines have become widespread and have provided alternative solutions to engineering problems. Image processing technology (IPT) and artificial neural networks (ANNs) are types of artificial intelligence methods. However, IPT and ANN have been used together in extremely few studies. In this study, these two methods were used to determine the compressive strength of concrete, a complex material whose mechanical features are difficult to predict. Sixty cube-shaped specimens were manufactured, and images of specific features of the specimens were taken before they were tested to determine their compressive strengths. An ANN model was constituted as a result of the process of digitizing the images. In this way, the two different artificial intelligence methods were used together to carry out the analysis. The compressive strength values of the concrete obtained via analytical modeling were compared with the test results. The results of the comparison $\left(R^{2}=0.9837-0.9961\right)$ indicate that the combination of these two artificial intelligence methods is highly capable of predicting the compressive strengths of the specimens. The model's predictive capability was also evaluated in terms of several statistical parameters using a set of statistical methods during the digitization of the images constituting the artificial neural network.
\end{abstract}

Key words: Strength, concrete, image processing, neural network, nondestructive testing, statistical properties/methods, cross validation, analytical modelling

Received: February 18, 2014

DOI: $10.14311 / \mathrm{NNW} .2015 .25 .016$

Revised and accepted: June 21, 2015

\footnotetext{
*Gamze Doğan, Faculty of Engineering, Civil Engineering Department, Selcuk University, 42075 Konya, Turkey, Tel: +90 332223 2025, E-mail: gamze@selcuk.edu.tr

$\dagger$ Musa Hakan Arslan - Corresponding Author, Faculty of Engineering, Civil Engineering Department, Selcuk University, 42075 Konya, Turkey, Tel.: +90 332223 2660, Fax: +90 33224106 35, E-mail: mharslan@selcuk.edu.tr

${ }_{\ddagger}^{\ddagger}$ Murat Ceylan, Faculty of Engineering, Department of Electrical-Electronics Engineering, Selcuk University, 42075 Konya, Turkey, Tel.: +90 332223 1920, Fax: +90 33224106 35, E-mail: mceylan@selcuk.edu.tr
} 


\section{Introduction}

An important aspect of determining whether an existing concrete building or one that is under construction has sufficient capacity to withstand earthquake and vertical loadings is determining the features of the concrete used in the building. Concrete is a construction material obtained by mixing sand, gravel or crushed stone, cement and water in certain proportions. The strength of concrete can be assumed to be high and to depend primarily on the components of the mix and the conditions under which it hardens. The most important mechanical characteristic of concrete is its compressive strength.

The fact that the compressive strength of concrete is one of the main parameters in the design of concrete structures is the reason that compressive strength is universally accepted as a universal gauge of concrete quality. Compressive strength testing is perceived to be easier than other types of strength tests. The compressive strength of concrete depends on constitution of concrete classes.

The compressive strength of concrete is traditionally measured at 28 days by testing cylinders $15 \mathrm{~cm}$ in diameter and $30 \mathrm{~cm}$ in height or cubes that are $15 \times$ $15 \times 15 \mathrm{~cm}$, cured under controlled conditions (e.g., at $20 \times C \pm 2 \times C$ in limesaturated water) [34]. Many factors, such as the quality of the cement, the watercement ratio, the curing conditions, the specimen dimensions, the granulometry of the aggregate, the use of a concrete mixer in producing the concrete, admixture materials added to concrete mixture, and the void ratio affect the compressive strength of concrete.

The methods used to determine the strength of the concrete in a building can be classified in two groups; destructive methods (such as core specimen sampling and testing, mounted specimen using method, penetration resistance tests, and break-off tests) and nondestructive methods (Schmidt hammer testing, ultrasonic testing, resonant frequency testing, sound wave velocity testing and pin penetration testing) $[1,7,8,14,17,19,23,27]$. In addition to the traditional methods, many other nondestructive test methods have been developed recently. One example is the use of image processing technology (IPT) together with artificial neutral networks (ANN). Image processing is a computer process of digitizing measured or saved electronic (digital) image data using computer hardware and software [11]. An ANN is an artificial neural network modeled on the human brain. The ANN method involves a process similar to the work done between the neurons in the brain. The output signal for a given input pattern is generated, and this signal is transmitted to the other cells in the network.

ANN is a popular approach to solving difficult and time-consuming engineering problems. ANNs have been developed to perform many different problems in areas in structural engineering such as structural analysis and design, structural dynamics and control, and structural damage assessment. The relevant literature includes a number of studies on the use of ANN and IPT in civil engineering problems. For instance, Arslan et al. [2] estimated reduction factors for prefabricated single bay-single story reinforced concrete (RC) buildings using ANN with $81 \%$ accuracy. Arslan [4] determined the torsional strength of RC beams using various ANN algorithms and showed that the ANNs were better able to predict the torsional strength of the beams than conventional and code approaches. Ko- 
roglu et al. [21] used combined artificial neural networks (CANNs) to estimate the flexural capacity of quadrilateral fiber-reinforced polymer (FRP) confined RC columns. The accuracies of the ANN models were found to be better than those of the conventional approaches described in the literature. Kose [22] investigated the parameters that affect the fundamental period of RC buildings with infill walls using ANN. Yuksel and Arslan [37] estimated RC silo design forces with ANN. IPT has also been applied to various civil engineering problems, as well as to problems in fields such as fingerprint analysis, facial recognition technology, biomedicine, chemistry, veterinary medicine, telecommunications, urban studies, medicine, space programs, nuclear medicine, biology, geology, archeology, astronomy, defense and industrial applications $[12,15,24,35,36]$. The majority of these applications have involved the determination of material properties. IPT can also be used in various sub-disciplines of civil engineering [16,25,26,30,31].

Studies of the aggregate used in concrete and the compressive strength of concrete using IPT have demonstrated the applicability of IPT to characterizing concrete and its contents. In studies by Basyiğit et al. [7] the compressive strength of concrete was estimated by applying IPT to concrete cube specimens. In a study by Ozen [27] the relations between aggregate shape parameters and the compressive strength of concrete were examined using digital image processing.

In this study, IPT and ANN were used together, unlike in other studies described in the literature. In this paper, after a brief explanation of IPT and ANN, the experimental and analytical study conducted to determine the compressive strength of concrete via the combined IPT-ANN method is described. The accuracy of the predictions obtained and the advantages and disadvantages of the method are reviewed from a critical perspective. The method is also compared with other traditional methods described in the literature.

\section{Image processing and artificial neural network}

The use of artificial intelligence methods to find solutions to engineering problems and offer alternatives to traditional methods and techniques is becoming more widespread. IPT and ANN are among such artificial intelligence methods. In this study, these two types of artificial intelligence methods were used together.

\subsection{Image processing technology (IPT)}

The use of image processing methods to examine surface images of engineering materials to determining the materials' features and load-bearing capacities has been researched in recent years. The main reasons for this are the fact that such measurements can be made with no contact with specimen surfaces and the fact that the desired results can be obtained without expensive and complex testing equipment.

Image processing is the study of the adaptation of the human eye's vision physiology to computer systems. The conversion of images encountered in daily life to digital images is a process of obtaining a new image as a result of changing (impro- 
vising) various features of the original image. Image processing methods consist of many processes, such as capturing images, digitizing, improvising and classifying.

Digital image processing methods have gained importance in two main areas of usage. The first area is the provision of image data to improve interpretation, and the second area is the processing of images via activities such as storage, communicating, screening and automatic detection processes.

In a digital image, the numbers assigned to each pixel reflect the radiance at that point. The conversion process is called digitization. For each pixel, the radiance of the image is sampled and evaluated computationally. Digitization of an image obtained from nature is illustrated in Fig. 1.

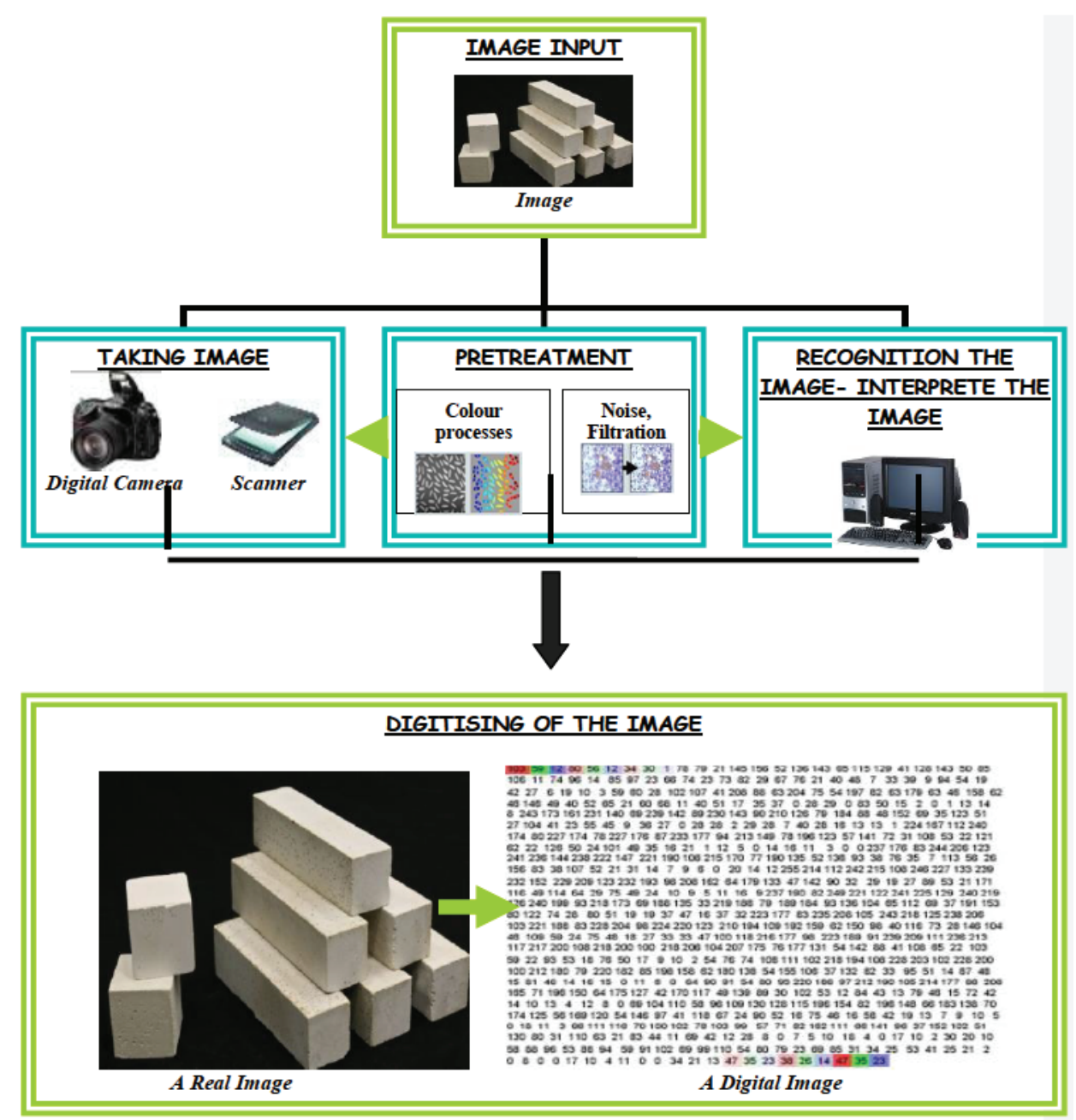

Fig. 1 Digitizing of the image taken from the nature. 


\subsection{Artificial neural network (ANN)}

ANNs use properties similar to some of the organizational principles of the human brain [32]. ANN represents the new generation of information processing systems. An ANN can examine examples of events, make generalizations about the related events, collect information and make decisions about new examples that it has never seen using the information it has learned. In general, ANN is successful in operations such as model selection and classification, function prediction, finding the best value and data classification $[10,18]$. ANN has been used to solve many complex problems, particularly in the field of engineering, but has found a limited number of applications in architectural science [13].

In this study, a three-layered feed-forward neural network was developed and trained using the error back-propagation method. The structure of a feed-forward multilayer network is illustrated in Fig. 2. The general structure of a neural network consists of an input layer, one or more hidden layer(s) (HN) and an output layer. In a three-layer network, for example, the first layer has input neurons that send data via synapses to the second layer of neurons, which use more synapses to send data to the third layer of output neurons. Systems that are more complex have more layers of neurons, with some having multiple layers of input neurons and output neurons. The synapses store parameters called weights that manipulate the data in the calculations. Three types of parameters typically define an ANN: a) the interconnection pattern between different layers of neurons, b) the learning process for updating the weights of the interconnections, and c) the activation function that converts a neuron's weighted input to its output activation. The layers are fully interconnected, as shown by the lines in Fig. 2. The input data are presented to the ANN at the input layer and are processed in a forward direction through the hidden layer(s). The output of the ANN is computed at the output layer. This is known as a "feed-forward mechanism." In a feed-forward operation, the flow of information is from left to right. In scientific problems, the number of input and output parameters is generally determined by design requirements. However, the choice of the number of HN neurons is left to the user. There is no general rule for selecting the number of neurons in a hidden layer. The purpose of all learning algorithms is to determine the connection weightings that will best represent the relationship between the input data and the output data.

The training phase of an ANN is performed using an error back-propagation algorithm. In this study, the Levenberg-Marquart (LM) back-propagation training algorithms, which uses standard numerical optimization techniques, was employed. The LM algorithm was designed to approach second-order training speed without it being necessary to compute the Hessian matrix.

Data scaling is another important step in network training. In this study, linear scaling of the data between 0 and 1 was used:

$$
s_{x}=\frac{\left(z-z_{\min }\right)}{\left(z_{\max }-z_{\min }\right)} .
$$

Here, $s_{x}$ is the normalized value of the variable $z$, and $z_{\min }$ and $z_{\max }$ are the variable minimum and maximum values, respectively. 


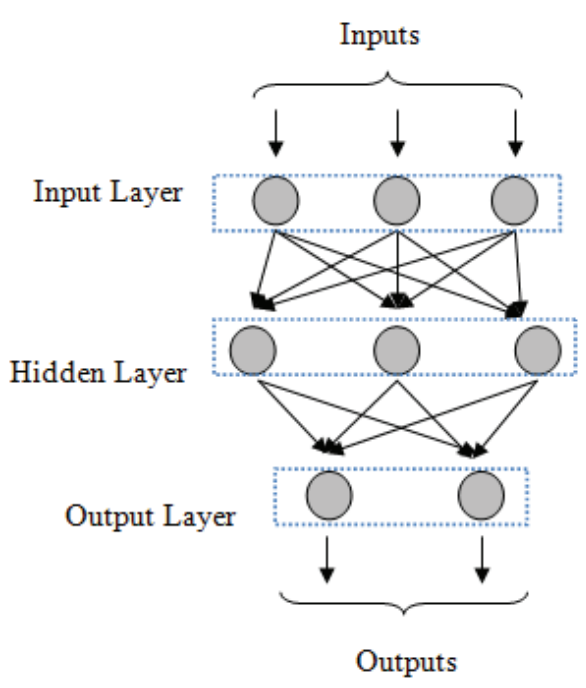

Fig. 2 ANN Architecture.

Training and test errors can be calculated using equations given in [28]. The following formula used in this study is also frequently used in literature:

$$
\text { Error }(\%)=\left(\frac{\sum_{i=1}^{k}|t(i)-a(i)|}{m \cdot n}\right) \cdot 100
$$

Here, $t(i)$ are the desired output values, $a(i)$ are the neural network outputs, $k$ is the data number in a set of training or test data, $m$ is the number of the segment in the training or test data, and $n$ is the number of neural network outputs for the training or test procedures.

\section{Formation of experimental data set}

An experimental data set was constituted to test the utility of image processing and ANN in prediction of the compressive strength of concrete. Sixty cube concrete specimens of different concrete classes and $15 \times 15 \times 15 \mathrm{~cm}$ in size were prepared to provide quantitative data for analysis [9]. In this study, CEM I 42.5 Portland cement was used. Concrete specimens with various cement dosages and watercement ratios were prepared, but not according to any systematic program. The water-cement ratios ranged from 0.4 to 0.6 , and the cement dosage ranged from 350 to $450 \mathrm{~kg} / \mathrm{m}^{3}$.

The samples were taken from 7 and 28 days cured concrete samples. On the $7^{\text {th }}$ day, various tests, not including pulse velocity tests, were carried out in accordance with the standards presented in TS EN 13791 [33], which addresses the design and construction of reinforced concrete structures. 
The surfaces of each cube specimen were photographed. The photographs of the specimens' surfaces that were in contact with steel bars were selected for use in the experiment, according to the rationale that these surfaces would be smoother than the other surfaces. The specimens selected and their photographed surfaces are presented schematically in Fig. 3, and the production process is illustrated in Fig. 4. The color photographs of both smooth surfaces of all the cube samples were taken at a distance of $20 \mathrm{~cm}$ using a Canon A3100 digital camera with 12.1megapixel resolution.

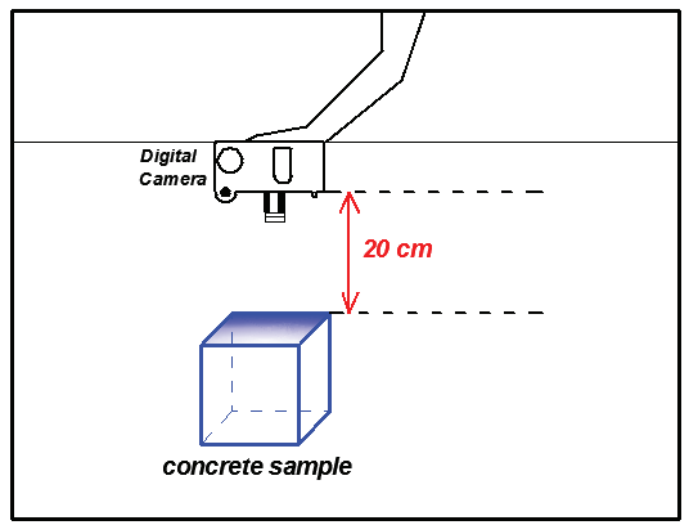

Fig. 3 Schematic view of experiment.
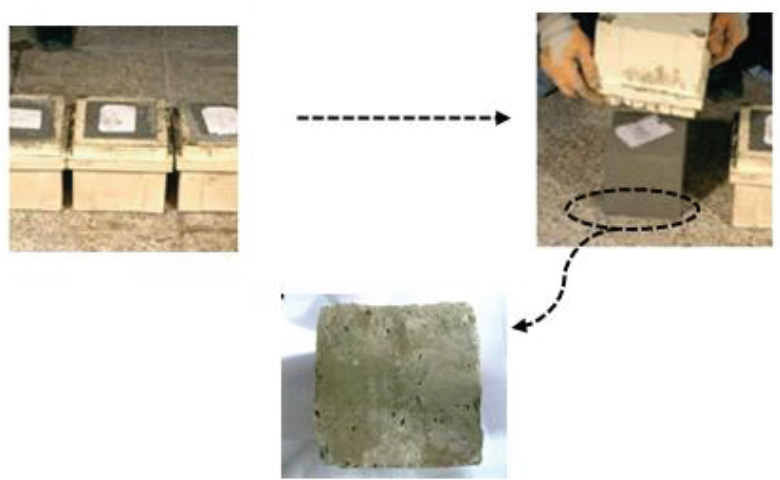

Fig. 4 Presentation of surface to which cube concrete sampling is applied.

Pulse velocity testing of the specimens in compression was conducted at 0.6 $\mathrm{MPa} / \mathrm{sec}$. The surface images of the cube specimens with significant strength values are presented at Fig. 5 .

To determine the compressive strengths of the concrete specimens, each specimen was tested in a compressive testing machine after being photographed, and the measured strength was noted. In Fig. 6, testing machine and measuring systems are given. 


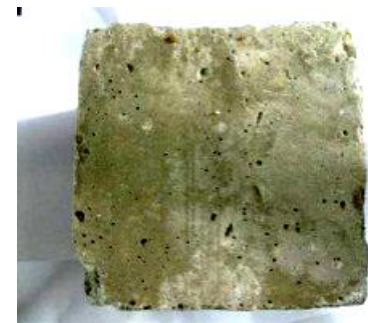

Image of sample whose compressive strength is $18,83 \mathrm{MPa}$

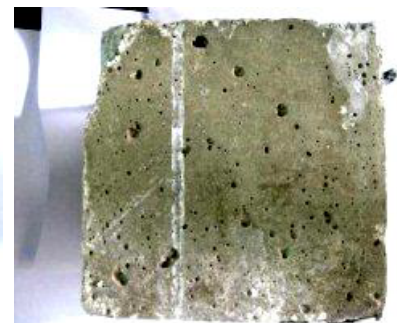

Image of sample whose compressive strength is $19,94 \mathrm{MPa}$

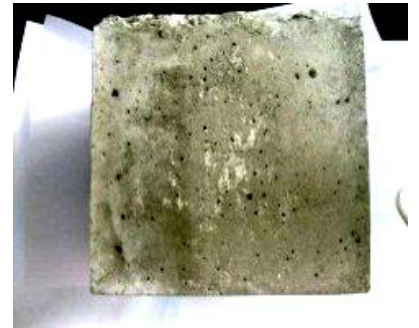

Image of samples whose compressive strength is $36,23 \mathrm{MPa}$

Fig. 5 Images of cube concrete samples.
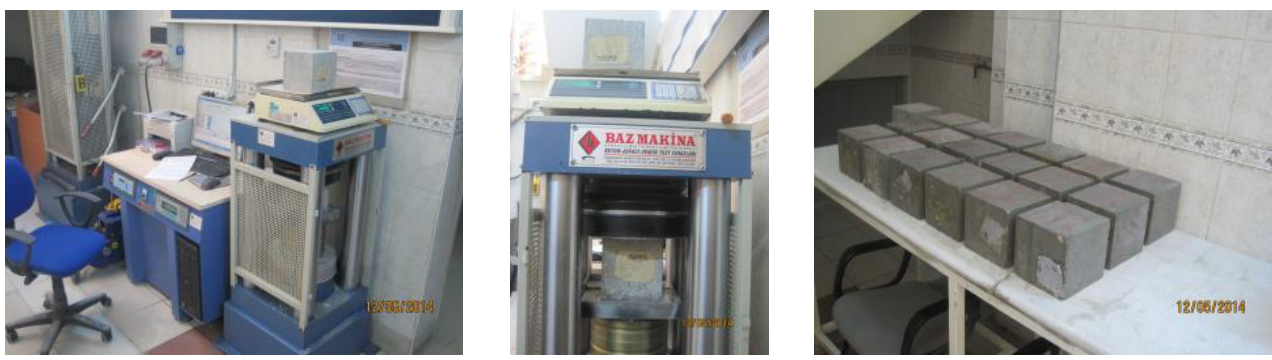

Fig. 6 Testing machine and measuring systems.

\section{Analysis approach}

In this study, the prediction of the compressive strengths of the concrete specimens was accomplished in two phases: digital image processing and ANN analysis. In contrast to the typical applications of one or the other of these two methods in the literature, image processing and ANN were used together. The MATLAB [20] was used to digitize the specimen images.

Using MATLAB's image processing functions, each of the image files was imported into the application platform as a matrix consisting of $[m \times n]$-dimensional pixels. The operations on this matrix were scanned as a picture of the matrix, obtained as a result of the algorithms applied.

The region of interest of the matrix to be processed was determined. For operational simplicity, a matrix consisting of gray values (0-255) was obtained by projection onto the first 2 dimensions of the 3-dimensional images. A histogram is the graphical expression of pixel values in an image and identities the pixels at each point in an image. The histograms of some of the tested concrete specimen images are shown in Fig. 7. In the diagrams, the $\mathrm{x}$ axis represents the pixel values in the image (0-255), and the y axis represents the pixel values' existence numbers in the image.

After this step, to symbolize each pixel, a $[3,000 \times 4,000]$-dimensional matrix was formed from the digital images of the concrete cube specimens used in the experiments by assigning a number corresponding to the radiance of each pixel. 
Doğan G., Arslan M.H., Ceylan M.: Statistical Feature Extraction...

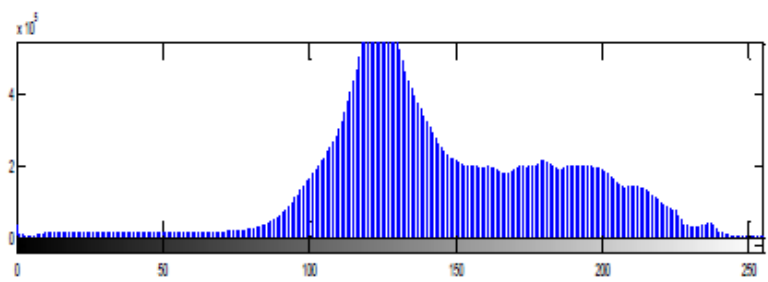

(a)

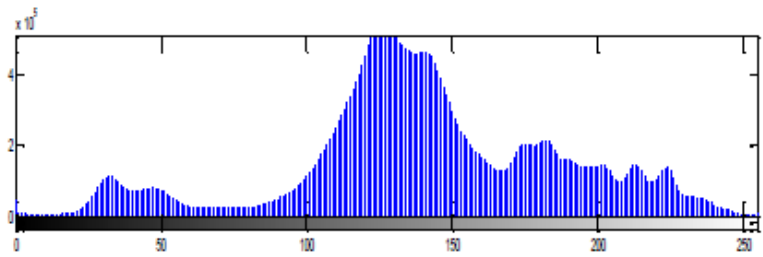

(b)

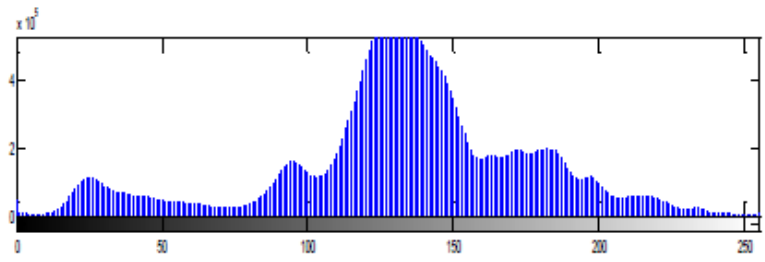

(c)

Fig. 7 The histogram of concrete image having 19,94 MPa compressive value (a), The histogram of concrete image having 36,23 MPa compressive value (b), The histogram of concrete image having 37,82 MPa compressive value (c).

As Fig. 8 shows, by obtaining two different edges in the specimen image, $10 \times 10$ sized matrices corresponding to these edges were developed. The concrete specimen images used in the experiment are in shades of gray, and 256 different gray shade values are used for image gaps with gray shades in image processing applications. Light-colored pixel values are closer to 255, while dark-colored areas are closer to 0. Fig. 9 presents a schematic illustration of the sample processing steps. Through the application of the digitizing process to each specimen image, the digital data were transformed into $[3,000 \times 4,000]$-dimensional matrix digital form suitable for ANN processing.

After the images were digitized in 3,000 $\times 4,000$-dimensional matrix form, the compressive strength of each specimen was predicted using the ANN structure. At this stage, the determination of the ANN structure to be used is crucial for the accuracy of this study. For this purpose, as discussed in the literature, the optimum number of hidden nodes and absorption ratio values constituting the structure of the network were determined by training and testing the ANN by trial and error. Furthermore, the optimum network form was determined by evaluating parameters such as the moment coefficient $\left(m_{c}\right)$ and iteration number (epochs), and the other elements of the ANN were evaluated by trial and error again. 


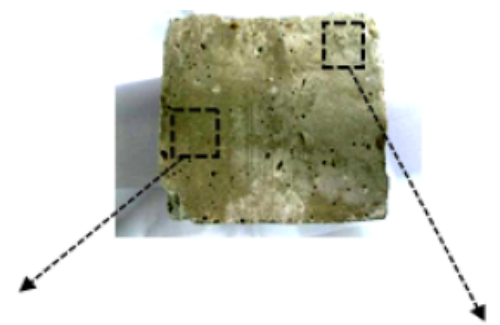

\begin{tabular}{|c|c|c|c|c|c|c|c|c|c|c|}
\hline & 1 & 2 & 3 & 4 & 5 & 6 & 7 & & & 10 \\
\hline & 22 & 23 & 21 & 19 & 18 & 21 & 22 & 21 & 23 & 21 \\
\hline & 26 & 23 & 20 & 20 & 24 & 27 & 23 & 17 & \begin{tabular}{|l}
18 \\
\end{tabular} & 17 \\
\hline & 27 & 24 & 21 & 21 & 24 & 27 & 23 & 17 & 18 & 19 \\
\hline & 28 & 27 & 25 & 21 & 19 & 21 & 21 & 20 & 23 & 27 \\
\hline & 30 & 30 & 28 & 24 & 21 & 21 & 21 & 20 & 24 & 30 \\
\hline & 32 & 31 & 29 & 28 & 28 & 28 & 23 & 17 & 21 & 29 \\
\hline & 31 & 30 & 29 & 27 & 27 & 28 & 26 & 22 & 21 & 27 \\
\hline & 27 & 30 & 29 & 25 & 20 & 22 & 27 & 29 & 23 & 26 \\
\hline & 30 & 26 & 23 & 25 & 29 & 31 & 30 & 29 & 27 & 24 \\
\hline & 29 & 26 & 23 & 23 & 25 & 25 & 24 & 24 & 23 & 21 \\
\hline
\end{tabular}

\begin{tabular}{|c|c|c|c|c|c|c|c|c|c|c|}
\hline & 1 & 2 & 3 & 4 & 5 & 6 & 7 & 8 & 9 & 10 \\
\hline I & 122 & 119 & 119 & 120 & 120 & 118 & 118 & 121 & 121 & 118 \\
\hline & 119 & 117 & 117 & 122 & 123 & 120 & 120 & 123 & 126 & 124 \\
\hline & 121 & 116 & 116 & 122 & 124 & 122 & 122 & 125 & 123 & 124 \\
\hline & 125 & 117 & 113 & 117 & 122 & 121 & 121 & 125 & 128 & 123 \\
\hline & 124 & 122 & 119 & 118 & 119 & 122 & 124 & 124 & 124 & 125 \\
\hline & 125 & 124 & 122 & 122 & 121 & 123 & 124 & 125 & 126 & 124 \\
\hline & 123 & 124 & 124 & 123 & 121 & 121 & 123 & 125 & 123 & 121 \\
\hline & 122 & 124 & 125 & 124 & 121 & 120 & 123 & 126 & 122 & 119 \\
\hline & 125 & 127 & 128 & 126 & 122 & 122 & 126 & 130 & 128 & 122 \\
\hline 0 & 128 & 129 & 128 & 126 & 123 & 123 & 127 & 130 & 129 & 12 \\
\hline
\end{tabular}

Fig. $810 \times 10$ matrix form of selected two different cross sectional areas.

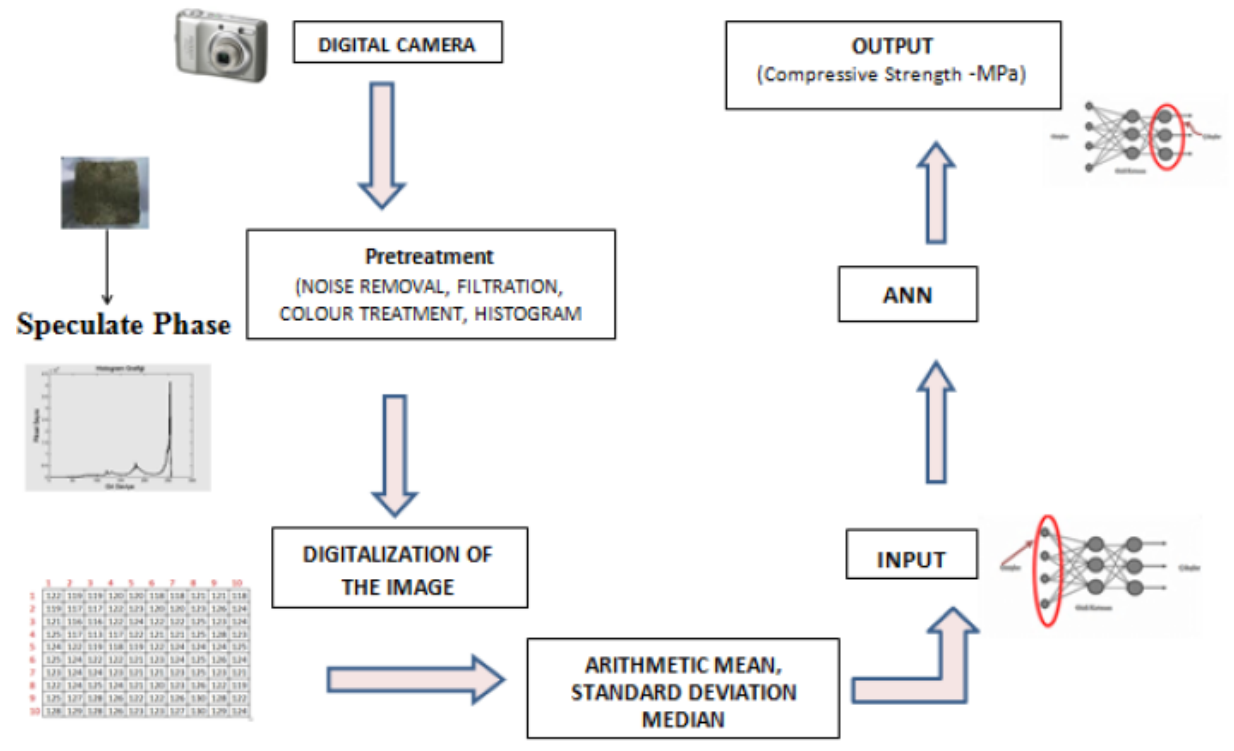

Feature Inference Phase

(Statistical Features)

Fig. 9 Schematic presentation of application sample testing steps.

Because the $3,000 \times 4,000$-dimensional matrix obtained from digitization of the images symbolize the ANN input, minimization of this matrix will decrease 
both the required number of iterations and the error margin. To minimize the matrix used as the ANN input, feature extraction was conducted by applying some statistical methods. In the ANN feature block, the accuracy percentage was determined using statistical measures such as the arithmetic mean, the standard deviation, and the median. The arithmetic mean is the central tendency of a collection of numbers determined as the sum of the numbers divided by the size of the collection. The median of a collection of numbers can be found by arranging the numbers from the lowest value to the highest value and picking the middle one. The standard deviation shows how much variation or dispersion exists in the collection of numbers.

In the feature extraction block, using statistical measures such as the average, standard deviation, and median of each column, the column can be expressed as a single digital value. In this way, the $3,000 \times 4,000$-dimensional matrixes were reduced to $1 \times 4,000$ dimensions. Furthermore, using the three mentioned statistical measures together, a different $3 \times 4,000$-dimensional matrix was obtained. The methods listed in Tab. I are grouped as ANN-1, 2, 3 and 4 methods.

\begin{tabular}{|c|c|c|c|c|c|c|c|c|}
\hline 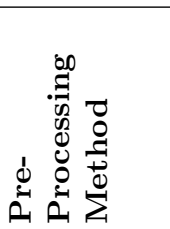 & 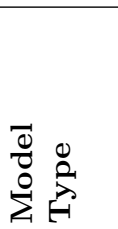 & 离 & 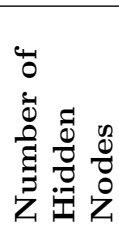 & 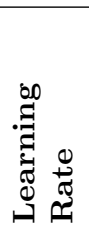 & 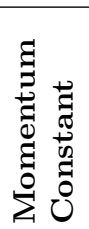 & 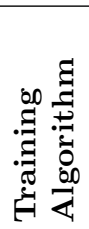 & 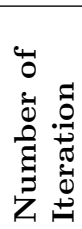 & 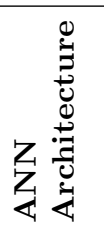 \\
\hline Mean & ANN- & $1 \times 400$ & 12 & 1.0 & 0.2 & LM & 2000 & $1: 12: 1$ \\
\hline $\begin{array}{l}\text { Standar } \\
\text { Deviati }\end{array}$ & ANN-2 & $1 \times 4000$ & 8 & 1.0 & 0.2 & LM & 2000 & $1: 8: 1$ \\
\hline & & & $2 b$ & 1.0 & 0.2 & $\overline{\mathrm{LI}}$ & 2000 & \\
\hline Together & ANN-4 & $3 \times 4000$ & 14 & 1.0 & 0.2 & LM & 2000 & 1:14: \\
\hline
\end{tabular}

Tab. I Optimum parameters used in ANN structures.

Through the feature extraction operation, an ANN network model was built using the average, standard deviation and median values of the matrix separately and together. Arslan et al. [6] predicted the earthquake performance of buildings using ANN by applying feature extraction to achieve a notable accuracy rate.

It is known that the number of hidden nodes greatly affects the performance of an ANN. Hence, tests were conducted with between 0 and 80 hidden nodes to determine the optimum number of hidden nodes. It was observed that a node number of 1.0 require the least training and yielded the smallest mistakes after the learning rate was increased in increments from 0.001 to 5.0, provided that the optimum hidden node was pegged. It was also observed that the iteration number at which the moment coefficient $\left(m_{c}\right)$ becomes 0.2 was 2,000 .

Arslan [3,5] observed that different back-propagation algorithms affect ANN results in different ways. In this study, only the Levenberg-Marquardt (LM) backpropagation algorithm was used to train the ANN. The total data was equally divided into training and testing data sets, and the outputs of the networks were determined as the value of compressive strength of concrete $\left(f_{c}\right)$. First of all, the input data was normalized to [0 1$]$ for the utilization of the logarithmic sigmoid 
function used in ANN as the activation function whose minimum and maximum values were 0 and 1 , respectively. Then, the two-fold cross-validation was implemented to the total data set. At first, the training and testing procedures were carried out, and then the testing data was used for the training process of ANN and the training data was used for the testing process of ANN. The advantage of using cross-validation method is that all the data can be used for training, i.e. none has to be held back in a separate test set. In this study, the two-fold crossvalidation method illustrated in Fig. 10 was used for obtaining a better network generalization. The obtained training and testing errors determined according to Eq. (2) were averaged and given in tables and figures. Values of parameters for the optimum ANN structures are presented in Tab. I.

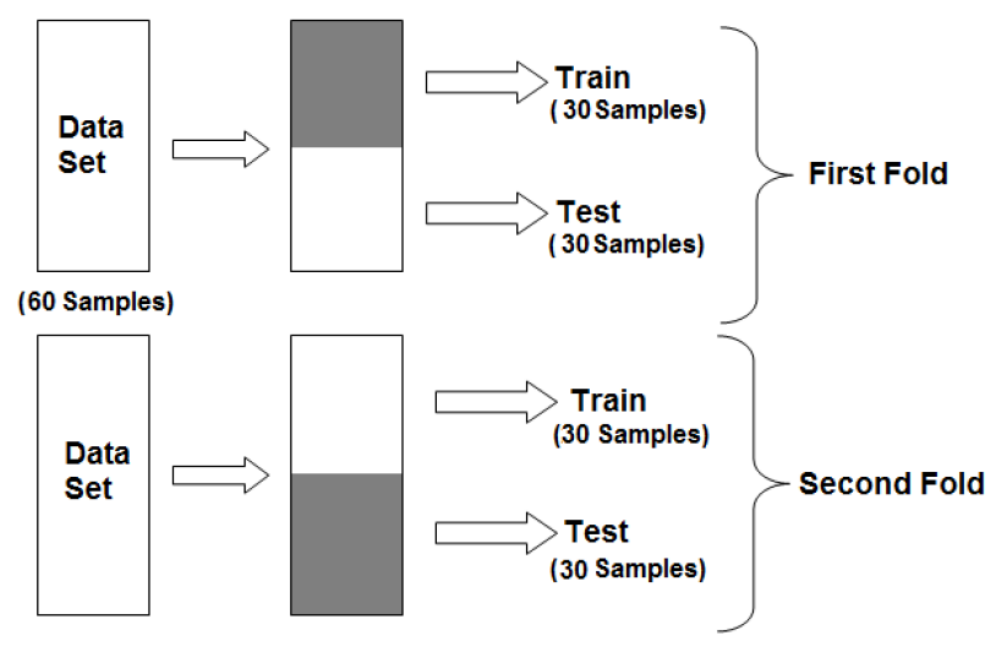

Fig. 10 Procedure of two-fold cross-validation.

\section{Results}

The outputs from the ANN are the predicted values of the compressive strengths of the concrete specimens in MPa. The strength values predicted by the ANN and the values obtained from the laboratory test of the concrete specimens are given in Tab. II. ANN-estimated values are given separately in Tab. II for each method. The estimated results are similar. The ANN-4 method, in which only average values are used, yields the best strength predictions. Although the similarity of the results prevents identification of one method as being superior to the others, the importance of feature extraction becomes apparent in considering the positive effects of the low matrix dimensions of the ANN-1, ANN-2, and ANN-3 methods on the processing time.

The laboratory-measured and ANN-predicted concrete compressive strengths are compared in Fig. 11 and Fig. 12. A regression analysis of the measured and predicted values was conducted to assess the quality of the ANN predictions. 
Doğan G., Arslan M.H., Ceylan M.: Statistical Feature Extraction...

\begin{tabular}{|c|c|c|c|c|c|}
\hline \multirow{2}{*}{$\begin{array}{c}\text { Sample } \\
\text { ID }\end{array}$} & \multirow{2}{*}{$\begin{array}{l}\mathbf{f}_{\mathbf{c E X P}} \\
{[\mathrm{MPa}]}\end{array}$} & \multicolumn{4}{|c|}{$\mathbf{f}_{\text {c PREDICTED }}[\mathrm{MPa}]$} \\
\hline & & $f_{c \text { ANN }-1}$ & $\mathbf{f}_{\mathrm{cANN}-2}$ & $\mathbf{f}_{\mathrm{cANN}-3}$ & $\mathrm{f}_{\mathrm{cANN}-4}$ \\
\hline 1 & 19.94 & 20.04 & 19.50 & 19.06 & 20.14 \\
\hline 2 & 18.83 & 18.92 & 18.41 & 18.00 & 19.01 \\
\hline 3 & $18.5^{7}$ & 18.66 & 18.16 & 17.75 & 18.35 \\
\hline 4 & 20.25 & 20.35 & 19.80 & 19.36 & 20.45 \\
\hline 5 & 20.14 & 20.03 & 19.69 & 19.25 & 19.89 \\
\hline 6 & 18.22 & 18.12 & 17.82 & 19.02 & 18.40 \\
\hline 7 & 16.32 & 16.23 & 15.96 & 17.03 & 16.13 \\
\hline 8 & 16.11 & 16.03 & 16.46 & 15.40 & 16.27 \\
\hline 9 & 36.23 & 36.04 & 37.02 & 37.82 & 36.59 \\
\hline 10 & 36.34 & 36.15 & 37.14 & 37.94 & 35.90 \\
\hline 11 & 37.14 & 37.32 & 36.32 & 38.77 & 36.69 \\
\hline 12 & 33.26 & 33.42 & 32.52 & 34.72 & 33.59 \\
\hline 13 & 35.53 & 35.70 & 34.74 & 37.09 & 35.10 \\
\hline 14 & 37.82 & 38.01 & 38.65 & 39.48 & 37.36 \\
\hline 15 & 23.40 & 23.51 & 23.91 & 24.42 & 23.63 \\
\hline 16 & 20.36 & 20.46 & 20.80 & 21.25 & 20.11 \\
\hline 17 & 20.30 & 20.40 & 20.74 & 21.19 & 20.51 \\
\hline 18 & 22.98 & 22.89 & 23.28 & 23.78 & 22.51 \\
\hline 19 & 24.60 & 24.72 & 25.14 & 23.51 & 24.30 \\
\hline 20 & 20.79 & 20.89 & 21.24 & 19.87 & 21.00 \\
\hline 21 & 25.12 & 24.99 & 25.67 & 24.01 & 24.82 \\
\hline 22 & 26.99 & 26.85 & 27.58 & 25.80 & 27.26 \\
\hline 23 & 25.61 & 25.48 & 26.17 & 24.48 & 25.31 \\
\hline 24 & 28.00 & 27.79 & 28.13 & 27.50 & 27.78 \\
\hline 25 & 28.88 & 29.13 & 28.20 & 26.93 & 29.03 \\
\hline 26 & 30.52 & 31.11 & 30.57 & 29.22 & 30.13 \\
\hline 27 & 30.69 & 30.38 & 31.03 & 29.17 & 31.22 \\
\hline 28 & 30.79 & 31.12 & 28.50 & 30.13 & 28.98 \\
\hline 29 & 31.80 & 31.80 & 31.80 & 31.80 & 31.80 \\
\hline 30 & 31.09 & 32.12 & 30.78 & 31.69 & 32.26 \\
\hline 31 & 31.59 & 30.96 & 32.53 & 32.83 & 31.44 \\
\hline 32 & 31.84 & 31.20 & 32.79 & 34.06 & 31.69 \\
\hline 33 & 32.09 & 31.44 & 33.05 & 33.33 & 32.94 \\
\hline 34 & 32.28 & 32.63 & 32.24 & 34.53 & 32.13 \\
\hline 35 & 32.71 & 31.05 & 33.69 & 34.99 & 32.56 \\
\hline 36 & 32.74 & 32.08 & 33.72 & 33.03 & 32.59 \\
\hline 37 & 35.88 & 35.16 & 36.95 & 35.39 & 35.75 \\
\hline 38 & 37.4 & 36.65 & 38.52 & 38.01 & 37.23 \\
\hline 39 & 37.49 & 38.74 & 37.61 & 39.11 & 38.32 \\
\hline 40 & 38.00 & 37.24 & 39.14 & 39.66 & 38.82 \\
\hline 41 & 38.90 & 39.12 & 39.06 & 40.62 & 39.72 \\
\hline 42 & 38.31 & 37.54 & 39.45 & 40.99 & 38.13 \\
\hline 43 & 38.65 & 37.87 & 39.80 & 40.35 & 38.47 \\
\hline 44 & 38.68 & 37.90 & 39.84 & 40.38 & 38.50 \\
\hline 45 & 39.58 & 38.78 & 41.76 & 41.35 & 39.40 \\
\hline
\end{tabular}




\begin{tabular}{|l|l|l|l|l|l|}
\hline $\mathbf{4 6}$ & 39.88 & 39.08 & 41.07 & 40.67 & 39.70 \\
\hline $\mathbf{4 7}$ & 40.16 & 39.35 & 41.36 & 42.97 & 39.97 \\
\hline $\mathbf{4 8}$ & 40.82 & 40.00 & 42.04 & 43.67 & 40.63 \\
\hline $\mathbf{4 9}$ & 41.78 & 40.94 & 43.03 & 42.70 & 41.59 \\
\hline $\mathbf{5 0}$ & 41.81 & 40.97 & 42.06 & 43.73 & 41.62 \\
\hline $\mathbf{5 1}$ & 43.44 & 42.57 & 44.74 & 45.48 & 43.24 \\
\hline $\mathbf{5 2}$ & 43.95 & 43.07 & 44.26 & 44.02 & 43.75 \\
\hline $\mathbf{5 3}$ & 44.21 & 43.32 & 45.53 & 46.30 & 45.01 \\
\hline $\mathbf{5 4}$ & 45.06 & 44.15 & 46.41 & 47.21 & 44.85 \\
\hline $\mathbf{5 5}$ & 45.40 & 44.49 & 46.76 & 47.57 & 46.19 \\
\hline $\mathbf{5 6}$ & 46.06 & 45.13 & 45.44 & 47.28 & 45.85 \\
\hline $\mathbf{5 7}$ & 46.45 & 45.52 & 47.84 & 48.70 & 47.24 \\
\hline $\mathbf{5 8}$ & 46.80 & 45.86 & 47.20 & 48.07 & 46.58 \\
\hline $\mathbf{5 9}$ & 47.23 & 46.28 & 48.64 & 47.53 & 47.01 \\
\hline $\mathbf{6 0}$ & 48.76 & 47.78 & 48.22 & 49.17 & 48.54 \\
\hline
\end{tabular}

Tab. II Concrete compressive strength values and presentation of estimated values obtained from model types of $A N N$.
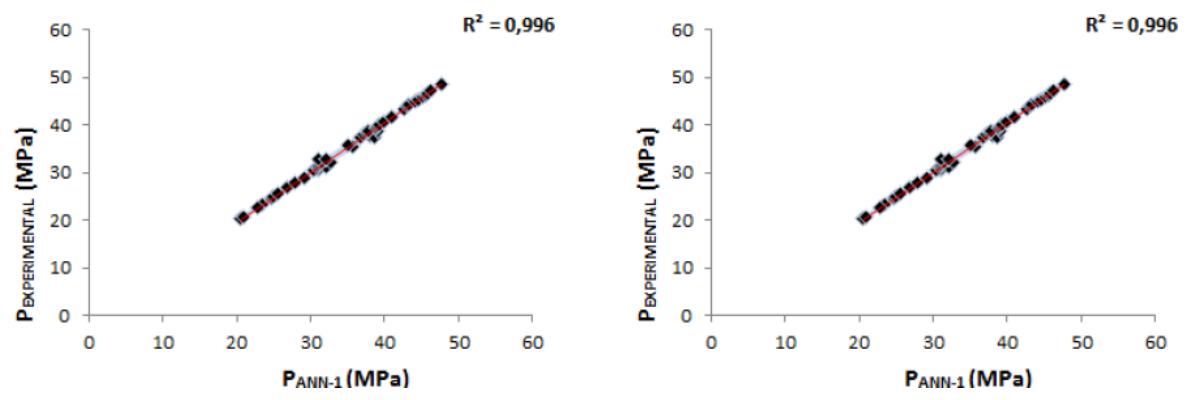

Fig. $11 R^{2}$ graph of experimental datas and results obtained from $A N N-1$ (a), $R^{2}$ graph of experimental data and results obtained from ANN-2 (b).
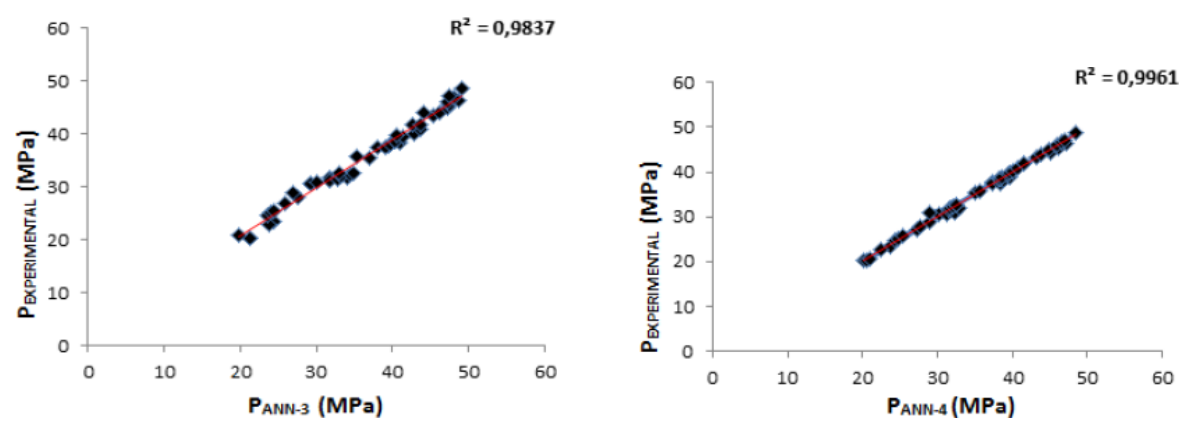

Fig. $12 R^{2}$ graph of experimental datas and results obtained from $A N N-3$ (a), $R^{2}$ graph of experimental datas and results obtained from $A N N-4$ (b). 


\section{Discussion}

In this study, a combination of the IPT and ANN methods was shown to be promising in predicting the compressive strength of concrete. Measured compressive strengths were compared to strengths predicted using the combined IPT-ANN method and were found to be similar. The relative error varies between $0.39 \%$ and $1.63 \%$. The accuracy of the results depends, of course, on the data set used.

Various factors that affect the compressive strength of concrete could be used in other such experiments. For example, a data set could be developed that included such parameters as the age of the concrete, the shape and geometry of the specimens, the loading rate of the testing machine, the water-cement ratio, the characteristics (shape, maximum size, and strength) of the aggregates used, any additives used during production of the concrete or added later, air void ratios, and curing conditions.

In this paper, authors have not aimed to see the parameters effect on image quality of concrete surface. It is well known that various factors affect the compressive strength of concrete and in the literature; many published papers have investigated these parameters' effects on concrete compressive strength. In addition, as far as author's knowledge there is no study on effects of parameters to image quality of concrete.

The features of the camera used to take the pictures of the specimens, the available light and the distance from which the pictures are taken may also affect the accuracy of this method. The camera used in this study, the distance between the camera and the specimens' surfaces, and the amount of light around the stage can all be considered parameters affecting the results of this study. In this study, the color photographs of both smooth surfaces of all the cube samples were taken at a distance of $20 \mathrm{~cm}$ using a digital camera with 12.1-megapixel resolution and in day light condition. The analyzed results of the picture taken from concrete samples are related to the distance between the camera and the specimens' surfaces, the amount of light around the stage and megapixel resolutions.

A comparison of this approach to predicting concrete compressive strength via image processing with other approaches [7, 29] indicates that there are differences between how the cube specimen pictures were taken in this study and how they have been taken in other studies. The cube specimens used in the other studies cited were cut into four pieces, and surface photos of each piece's edges were taken. A digital scanner was used to scan 6 different surfaces obtained while photographing each specimen, and the scanned images were worked on. The rationale for cutting the specimen to pieces is that the strength of the aggregate pieces and their dispersion in the concrete affect the compressive strength and provide more observations for use in determining the compressive strength. On the other hand, this approach to image processing is destructive, time-consuming and costly. The fact that the specimens are destroyed by being cut into pieces suggests that the method described in this paper may offer an alternative that is nondestructive, less time-consuming, and less costly.

The quality of the concrete is not related only to the surface quality, however, the surface quality of concrete gives an important clue about concrete mechanical properties. 


\section{Conclusions}

The results of this study, in which both IPT and ANN were used, show that a high correlation was obtained between concrete compressive strength values determined from experimental and analytical methods. This method, which is used to predict the compressive strength, the most important mechanical feature of concrete, yields positive results that supplement those of traditional methods. The strength values of concrete specimens predicted using this method were found to be very close to the strength values measured by destructive compression testing.

The method used in this study to predict the compressive strength of concrete using image processing and an artificial neural network would yield more reliable and accurate results if paired with other nondestructive methods to predict concrete compressive strength. However, the method mentioned in this study, should be calibrated by using many other parameters such as the aggregate distribution, void ratio, the feature of the cement paste, etc affect the compressive strength of concrete.

This method can be considered an alternative method for determining the compressive strength of concrete structural elements of existing reinforced concrete buildings. However, like other nondestructive test methods, this method must also be calibrated using core specimens taken from the existing reinforced concrete buildings.

The method proposed in this study is suitable for high-speed quality checking in a concrete production factory. As a current method in the literature, the method can be used with the other methods for verification.

\section{Acknowledgements}

This study was carried out within the framework of the Thesis Project (Gamze DOGAN) No 13101007 supported by the Selcuk University Unit of Scientific Research Projects Coordination. The authors are thankful to SU Unit of Scientific Research Project.

\section{References}

[1] AL-MUFTI R.L., FRIED A.N. The early age non-destructive testing of concrete made with recycled concrete aggregate. Construction and Building Materials. 2012, 37, pp. 379-386, doi: 10.1016/j.conbuildmat.2012.07.058.

[2] ARSLAN M.H., CEYLAN M., KALTAKCI M.Y., OZBAY Y., GULAY G. Prediction of force reduction factor $\mathrm{R}$ of prefabricated industrial buildings using neural networks. Structural Engineering and Mechanics. 2007, 27(2), pp. 117-34, doi: 10.12989/sem.2007.27.2.117.

[3] ARSLAN M.H. Application of ANN to evaluate effective parameters affecting failure load and displacement of RC buildings. Natural Hazards and Earth System Science Journal. 2009, 9, pp. 967-977, doi: 10.5194/nhess-9-967-2009.

[4] ARSLAN M.H. Prediction of torsional strength of RC beams by using different artificial neural network algorithms and building codes. Advances in Engineering Software. 2010, (41)7-8, pp. 946-955, doi: 10.1016/j.advengsoft.2010.05.009.

[5] ARSLAN M.H. Estimation of Curvature Ductility in Reinforced Concrete Buildings. KSCE Journal. 2012, 16(5), 759-770, doi: 10.1007/s12205-012-0958-1. 
[6] ARSLAN M.H., CEYLAN M., KOYUNCU T. An ANN Approaches on Estimating Earthquake Performances of Existing RC Buildings. Neural Network World. 2012, 5(12), pp. 443458, doi: 10.14311/NNW.2012.22.027.

[7] BASYIGIT C., COMAK B., KILICARSLAN S., UNCU I.S. Assessment of concrete compressive strength by image processing technique. Construction and Building Materials. 2012, 37, pp. 526-532, doi:10.1016/j.conbuildmat.2012.07.055.

[8] BOGAS J.A., GOMES M.G., GOMES A. Compressive strength evaluation of structural lightweight concrete by non-destructive ultrasonic pulse velocity method. Ultrasonics. 2012, 53(3), pp. 962-972 doi: 10.1016/j.ultras.2012.12.012.

[9] CANKAyA G., ARSLAN M.H., CEYLAN M. Statistical Methods for Processing and Analysis of Digital Images: Determining compressive strength of concrete. International Conference of Applied Statistics. 2012, Bled, Slovenia.

[10] CEYLAN M., ARSLAN M.H., CEYLAN R., KALTAKCI M.Y., OZBAY Y. A New Application Area of ANN and ANFIS: Determination of Earthquake Load Reduction Factor of Prefabricated Industrial Buildings. Civil Engineering and Environmental Systems. 2010, 27(1), pp. 53-69, doi: 10.1080/10286600802506726.

[11] COMAK B., BEYCIOGLU A., BASYIGIT C., KILICARSLAN S. The use of image processing techniques in concrete technology. 6th Intenational Advanced Technologies Symposium 2011 (IATS'11). 2011, Elazig, Turkey.

[12] DOGAROGLU O.K. Utilization opportunities of image processing technology in estimation of live weight and various body sizes of cattles for slaughter. Tekirdag, Turkey, 2006. Master Thesis, Trakya University Institute of Science in Tekirdag, Turkey.

[13] EKICI B.B., AKSOY U.T. Prediction of Building Energy Consumption by Using Artificial Neural Networks. Advances in Engineering Software. 2010, 40(5), pp. 356-362, doi: 10.1016/j.advengsoft.2008.05.003.

[14] ERGUN A., KURKLU G. Determination of concrete strength in current concrete buildings. Earthquake Symposium. 2005, Kocaeli, Turkey.

[15] FRUH C., SCHILDKNECHT T. Object image linking of earth orbiting object in the presence of comics. Advances in Space Research. 2012, 49, pp. 594-602, doi: 10.1016/j.asr.2011.10.021.

[16] GAYDECKI P., SILVA I., FERNANDES B.T., YU Z. Z. A portable inductive scanning system for imaging steel- reinforcing bars embedded within concrete. Sensors and Actuators. 2000, 84, pp. 25-32, doi: 10.1016/S0924-4247(99)00296-4.

[17] HASSAN A.M.T., JONES S.W. Non-destructive testing of ultra-high performance fibre reinforced concrete (UHPFRC): A feasibility study for using ultrasonic and resonant frequency testing techniques. Construction and Building Materials. 2012, 35, pp. 361-367, doi: 10.1016/j.conbuildmat.2012.04.047.

[18] HAYKIN S. Neural Networks: A comprehensive foundation. 2nd ed. New York: PrenticeHall, 1998.

[19] HOBBS B., KEBIR M.T. Non-destructive testing techniques for the forensic engineering investigation of reinforced concrete buildings. Forensic Science International. 2007, 167(2,3), pp. 167-172, doi: 10.1016/j.forsciint.2006.06.065.

[20] MATLAB. Matlab Reference Guide [online]. The MathWorks, Inc. Natick, MA, 1996 [viewed 2015-02-02]. Available from: http://www.mathworks.com/matlabcentral/

[21] KOROGLU M.A, CEYLAN M., ARSLAN M.H., ILKI A. Estimation of Fslexural Capacity of Quadrilateral FRP-Confined RC Columns Using Combined Artificial Neural Network. Engineering Structures. 2012, 42, pp. 23-32, doi: 10.1016/j.engstruct.2012.04.013.

[22] KOSE M.M., Parameters affecting the fundamental period of RC buildings with infill walls. Engineering Structure. 2009, 31(1), pp. 93-102, doi: 10.1016/j.engstruct.2008.07.017.

[23] KUCUK O.F. Ultrasonic surface waves - finding concrete strength with the help of Schmidt method. Sanliurfa, Turkey, 2006. Master Thesis, Harran University Institute of Science in Sanliurfa, Turkey. 
[24] MIDDLETON L., SIVASWAMY J. Edge detection in a hexagonal- image processing framework. Image and Vision Computing. 2001, 19(14), pp. 1071-1081, doi: 10.1016/S02628856(01)00067-1.

[25] NAGATAKI S., GOKCE A., SAEKI T., HISADA M. Assessment of recycling process induced damage sensitivity of recycled concrete aggregates. Cement and Concrete Research. 2004, 34(6), pp. 965-971, doi: 10.1016/j.cemconres.2003.11.008.

[26] NAMBIAR E.K.K., RAMAMURTHY, K. Air-void characterization of foam concrete. Cement and Concrete Research. 2007, 37(2), pp. 221-230, doi: 10.1016/j.cemconres.2006.10.009.

[27] OKUYAN M.N. The fact that compressive strength of high resistant concrete including silica fume is non-damaged, Master Thesis 2007, Harran University Institute of Science in Sanliurfa, Turkey.

[28] OZBAY Y., CEYLAN R., KARLIK B.A. A fuzzy clustering neural network architecture for classification of ECG arrhythmias. Computers in Biology and Medicine. 2006, 36(4), pp. 376-388, doi: 10.1016/j.compbiomed.2005.01.006.

[29] OZEN M. Investigation of relationship between aggregate shape parameters and concrete strength using imaging techniques. Ankara, Turkey, 2007. Master Thesis, Graduate School of Natural and Applied Sciences of Middle East Technical University in Ankara.

[30] SCHUTTER G.D. Advanced monitoring of cracked structures using video microscope and automated image analysis. NDTEE International. 2002, 35(4), pp. 209-212, doi: 10.1016/S0963-8695(01)00042-1.

[31] SPYROU S., DAVISON J.B. Displacement measurement in studies of steel T-stub connections. Journal of Constructional Steel Research. 2001, 57(6), pp. 647-659, doi: 10.1016/S0143-974X(01)00003-7.

[32] Stevens R., IKedA J., CASillas A., PAlaCiO J., CLYMAN S. Artificial Neural Network-Based Performance Assessments. Computers in Human Behavior. 1999, 15(3-4), pp. 295-313, doi: 10.1016/S0747-5632(99)00025-4.

[33] Turkish Standards, TS EN 13791. Assessment of in-situ compressive strength in structures and precast concrete components. Turkish Standards Institute 2010, Ankara.

[34] Turkish Standards, TS 500. Design and Construction Rules of Concrete. Turkish Standards Institute 2000, Ankara.

[35] VERIM V. Finding tissue boundaries by using image processing methods. Ankara, Turkey, 2005. Master Thesis, Gazi University Institute of Science in Ankara, Turkey.

[36] WINDER R.J., MORROW P.J., MCRITCHIE I.N., BAILIE J.R., HART P.M. Algorithms for digital image processing in diabetic retinopathy. Computerized Medical Imaging and Graphics. 2009, 33(8), pp. 608-622, doi: 10.1016/j.compmedimag.2009.06.003.

[37] YUKSEL S.B., ARSLAN M.H. Design Forces for Groups of Six Cylindrical Silos by ANN. Structures \& Buildings Journal. 2012, 165(10), pp. 567-580, doi: 10.1680/stbu.10.00049. 